\title{
Frequency of Seaweed Intake and Its Association with Cardiovascular Disease Mortality: The JACC Study
}

\author{
Rie Kishida ${ }^{1,2}$, Kazumasa Yamagishi ${ }^{2}$, Isao Muraki ${ }^{1}$, Mizuki Sata ${ }^{3}$, Akiko Tamakoshi $^{4}$, Hiroyasu Iso ${ }^{1}$ \\ for the JACC Study Group
}

${ }^{1}$ Public Health, Department of Social Medicine, Osaka University Graduate School of Medicine, Osaka, Japan

${ }^{2}$ Department of Public Health Medicine, Faculty of Medicine, and Health Services Research and Development Center, University of Tsukuba, Ibaraki, Japan

${ }^{3}$ Department of Preventive Medicine and Public Health, Keio University School of Medicine, Tokyo, Japan

${ }^{4}$ Department of Public Health, Hokkaido University, Graduate School of Medicine, Sapporo, Japan

Aim: Seaweed is a popular traditional foodstuff in Asian countries. To our knowledge, few studies have examined the association of seaweed intake with mortality from cardiovascular disease. We examined the association of frequency of seaweed intake with total and specific cardiovascular disease mortality.

Methods: We examined the association of seaweed intake with mortality from cardiovascular disease among 40,234 men and 55,981 women who participated in the Japan Collaborative Cohort Study for Evaluation of Cancer Risk. Sex-specific hazard ratios for mortality from cardiovascular disease (stroke, stroke subtypes, and coronary heart disease) according to the frequency of seaweed intake were calculated stratified by study area and adjusted for potential cardiovascular risk factors and dietary factors.

Results: During the 1,580,996 person-year follow-up, 6,525 cardiovascular deaths occurred, of which 2,820 were due to stroke, and 1,378, to coronary heart disease. Among men, the multivariable analysis showed that participants who ate seaweed almost every day compared with those who never ate seaweed had hazard ratios (95\% confidence interval; $P$ for trend) of $0.79(0.62-1.01 ; 0.72)$ for total cardiovascular disease, $0.70(0.49-0.99$; $0.47)$ for total stroke, $0.69(0.41-1.16 ; 0.11)$ for cerebral infarction. Among women, the multivariable-adjusted hazard ratios were $0.72(0.55-0.95 ; 0.001)$ for total cardiovascular disease, $0.70(0.46-1.06 ; 0.01)$ for total stroke, and $0.49(0.27-0.90 ; 0.22)$ for cerebral infarction. No associations were observed between seaweed intake and risk of intraparenchymal hemorrhage and coronary heart disease among either men or women.

Conclusions: We found an inverse association between seaweed intake and cardiovascular mortality among Japanese men and women, especially that from cerebral infarction.

Key words: Seaweed, Cohort study, Total cardiovascular disease

\section{Introduction}

Seaweed has gained increasing interest for its potential role in cardiovascular disease (CVD) prevention $^{1,2}$. Seaweed contains dietary fibers, peptides, and carotenoids that have beneficial effects on cardiovascular risk factors including blood pressure ${ }^{3-7)}$, serum lip$\mathrm{ids}^{8-10)}$, and fatty $\operatorname{acid}^{11)}$, blood glucose ${ }^{12)}$, and body weight ${ }^{9,13,14)}$. However, the health effect due to the combination of these nutrients and other nutrients as food is largely known.

Seaweed is a popular traditional foodstuff in Asian countries, including Japan, Korea, and parts of China. For example, on average, Japanese population consumes $9.9 \mathrm{~g}$ of seaweed a day ${ }^{15}$. Japan's longest life expectancy and the lowest CVD mortality in the world ${ }^{16)}$ could be due to their unique dietary patterns ${ }^{17)}$, which are partly characterized by regular

Address for correspondence: Hiroyasu Iso, Department of Social Medicine, Osaka University Graduate School of Medicine, 2-2 Yamadaoka, Suita, Osaka 5650871, Japan E-mail: iso@pbhel.med.osaka-u.ac.jp

Received: October 5, 2019 Accepted for publication: January 8, 2020

Copyright@2020 Japan Atherosclerosis Society

This article is distributed under the terms of the latest version of CC BY-NC-SA defined by the Creative Commons Attribution License. 
intake of seaweed ${ }^{18,19)}$.

However, few studies have examined the association of seaweed intake with mortality or morbidity from $\mathrm{CVD}^{20)}$. It is worth analyzing that association as an important topic in nutritional epidemiology.

Therefore, we investigated here the association of frequency of seaweed intake with total and specific CVD mortality, including total stroke, stroke subtypes (intraparenchymal and subarachnoid hemorrhages and cerebral infarction), and coronary heart disease (CHD) in Japanese.

\section{Methods}

\section{Study Cohort}

The Japan Collaborative Cohort Study for Evaluation of Cancer Risk (JACC study) was a cohort study sponsored by the Japanese Ministry of Education, Culture, Sports, Science and Technology that comprised a nationwide community-based sample of 110,585 persons (46,395 men and 64,190 women) aged 40 to 79 years during the baseline period (19881990) from 45 communities in Japan, as described elsewhere in detail ${ }^{21)}$. The study participants completed self-administered questionnaires about their lifestyles, including food intake, and medical histories of CVD or cancer. The participants, methods, measurements, and statistical analyses of the present study were basically the same as those reported in a previous JACC publication ${ }^{21)}$. Briefly, we excluded persons who reported a history of heart disease, stroke, or cancer at baseline $(n=6,234)$ and those with incomplete answers for seaweed intake in the dietary questionnaire $(n=8,136)$. Finally, a total of 96,215 individuals $(40,234$ men and 55,981 women) participated in the analyses.

\section{Seaweed Intake}

The frequency of seaweed intake during the previous year was assessed by food frequency questionnaire (FFQ) from "never," "1 to 2 times a month," "1 to 2 times a week," "3 to 4 times a week," and "almost every day." The actual amount of seaweed is difficult to estimate since it is consumed usually as a hot water extract in soup, a flavoring for other foods (dashi), a condiment, or a side dish. However, good reproducibility and validity of the questionnaire were reported (Spearman correlation coefficients of reproducibility $=$ 0.66 and validity $=0.46)^{22}$. In nutritional epidemiology, this level of correlation coefficient is considered acceptable for the evaluation of food intake ${ }^{23)}$. The FFQ included 33 food items and five choices for frequency of intake offered for each item ${ }^{22}$. The amounts of nutrients consumed were calculated by multiplying the frequency scores and estimated nutrients for each portion and summing across all 33 items. The details of the validation study and methods for the estimation of nutrient factors were reported previously ${ }^{22)}$. This FFQ showed moderate validity in many nutrient items.

\section{Mortality Surveillance}

The cause and date of death were systematically obtained from death certificates. In Japan, registration of death is required by the Family Registration Law and is followed nationwide. Thus, all deaths that occurred in the cohort were confirmed by death certificates from a public health center, except for persons who died after they had moved from their original community, in which case, the participant was censored. The date of move-out of cohort members from the study area was verified by the investigator in cooperation with key members of the local governmental office. We continued follow-up from the time of the baseline survey through the end of 2009, with the exceptions of four communities through 1999, four communities through 2003, and two communities through 2008. We used the underlying cause of death coded by the 10th Revision of the International Statistical Classification of Diseases and Related Health Problems (ICD-10) to identify mortality endpoints: total stroke (I60-I69), including intraparenchymal hemorrhage (I61), subarachnoid hemorrhage (I60), and cerebral infarction (I63), CHD (I20-I25), and total CVD (I01-I99).

\section{Statistical Analysis}

We calculated age-adjusted means and proportions of selected cardiovascular risk factors and nutrients according to the frequency of seaweed intake, and the overall difference was tested by analysis of covariance. For each participant, we calculated the personyears of follow-up from baseline in 1988-1990 to the first endpoint (death, moving from the community, or the end of 2009). We tested the proportional hazards assumption in Cox regression using risk factors by time interactions and found it was not violated. The sex-specific hazard ratio (HR) with $95 \%$ confidence intervals (CIs) of each mortality outcome was calculated according to the frequency of seaweed intake by using the Cox proportional hazards models, stratifying jointly by areas (Hokkaido, Tohoku, Kanto, Chubu, Kinki, Chugoku, and Kyushu) and adjusting for age (continuous). In the multivariable model, we further adjusted for potential confounders, including body mass index (quintiles), history of hypertension and diabetes mellitus (yes or no), alcohol intake (never, former, current drinker of ethanol at 1-22, 23-45, 
46-68, or $69 \mathrm{~g}$ /day; $23 \mathrm{~g}$ ethanol corresponds to $1 \mathrm{go}$, a Japanese traditional unit for volume), smoking status (never, former, current smoker of 1-19, or 20 cigarettes/day), perceived mental stress (low, median, high, or extremely), daily walking time (rarely, 30, 30-60, or more than $60 \mathrm{~min} /$ day), sport participation (never, $1-2,3-4$, or $>5 \mathrm{~h} /$ week), education levels (age of completed education of $<13,13-15,16-18$, or $\geq 19$ years), and quartiles of total energy, vegetables, fruit, meat, fish, and salt intakes. Body mass index was calculated as body weight $(\mathrm{kg})$ divided by the square of height $\left(\mathrm{m}^{2}\right)$ and lifestyles, including weight, height, and histories of hypertension and diabetes, were derived from the self-reported baseline questionnaire. We used SAS version 9.4 software (SAS Institute, Cary, NC) for the analyses. All the probability values for the statistical tests were two-tailed, and values less than 0.05 were regarded as significant.

\section{Ethical Considerations}

Informed consent was obtained before the participants completed the questionnaire or sometimes from community leaders instead of individuals, which was a common practice for informed consent in Japan at that time. The JACC study protocol was approved by the institutional review boards of Hokkaido University (i 14-044), the University of Tsukuba (663), and Osaka University (14285).

\section{Results}

During the 1,580,996 person-year follow-ups, 6,525 deaths from CVD occurred $(3,315$ men and 3,210 women); of those, 2,820 were from stroke (1,423 men and 1,397 women), and 1,378 were from CHD (776 men and 602 women).

As shown in Table 1, seaweed intake was positively associated with age, history of diabetes, sports participation $>5 \mathrm{~h} /$ week, walking time $>1 \mathrm{~h} /$ day, and major nutrient intakes, whereas it was inversely associated with current smoking for both men and women. Seaweed intake was positively associated with current drinking for men but inversely for women. High perceived mental stress was inversely associated with seaweed intake only among men. No association was found between the history of hypertension and hours of sleep among either sex.

Table 2 shows the age-adjusted and area-stratified jointly and multivariable-adjusted HRs and 95\% CIs for mortality from stroke, stroke subtypes, CHD, and CVD according to the frequency of seaweed intake. Compared with participants who never ate seaweed, both men and women who ate almost every day had lower risk of mortality from total stroke, espe- cially cerebral infarction, and total CVD, although not always statically significant. Among men, the multivariable-adjusted HRs (95\% CIs; $P$ for trend) for those who never ate seaweed versus who ate seaweed almost every day were $0.70(0.49-0.99 ; 0.47)$ for total stroke, $0.69(0.41-1.16 ; 0.11)$ for cerebral infarction and $0.79(0.62-1.01 ; 0.72)$ for total CVD. The respective HRs among women were 0.70 (0.46-1.06; $0.01), 0.49(0.27-0.90 ; 0.22)$ and $0.72(0.55-0.95$; $0.001)$. No associations were observed between seaweed intake and risks of intraparenchymal hemorrhage and CHD among either men or women.

\section{Discussion}

We observed that persons who never ate seaweed intake had the higher mortality from total stroke, cerebral infarction, and total CVD, but not from $\mathrm{CHD}$, in this prospective cohort study of Japanese men and women. Our results strengthened the preliminary finding from the JACC study ${ }^{24)}$, which did not perform adjustments for potential confounding variables or stroke subtype classification.

A recent report from the Japan Public Health Center-Based Prospective (JPHC) study of middleaged Japanese study showed that seaweed intake was inversely associated with the risk of incident ischemic heart disease but not stroke ${ }^{20)}$. As for stroke, different results could be due to different categories of frequencies of seaweed intake. The discrepancy for the result of stroke between JPHC study and the present JACC study may be due to different lowest categories of seaweed intake (never versus $<1$ day/week). JPHC study did not differentiate the categories of never and $<1$ day/week in the questionnaire so that the excess risk of stroke in the lowest category of seaweed intake might not be detected, whereas the JACC study found the excess risk of stroke mortality. The discrepancy for the result of CHD may be due to the outcome (incidence versus mortality). As for CHD, validation studies have shown that approximately one-quarter of deaths from CHD as recorded on death certificates were misdiagnosed ${ }^{25,26)}$. Therefore, the association between seaweed intake and mortality from CHD might be weakened.

These epidemiological findings supported the result from animal experimental studies. Stroke-prone spontaneously hypertensive rats (SHRSPs) fed 10\% active fiber (powdered brown seaweed converted to potassium ions form) had the attenuation of development of severe hypertension and stroke compared with SHRSPs fed kaolin ${ }^{4}$. The SHRSPs fed 5\% wakame seaweed showed delayed developments of stroke and improved survival compared with the con- 
Table 1. Sex-specific age-adjusted baseline characteristics according to the frequency of seaweed intake

\begin{tabular}{|c|c|c|c|c|c|c|}
\hline & \multicolumn{6}{|c|}{ Seaweed intake } \\
\hline \multicolumn{7}{|l|}{$\operatorname{Men}(n=40,234)$} \\
\hline Number of subjects & 756 & 4,424 & 12,444 & 12,010 & 10,600 & \\
\hline Age, years & 56.7 & 55.7 & 56.2 & 56.9 & 58.6 & $<.001$ \\
\hline History of diabetes, $\%$ & 7.7 & 5.8 & 6.3 & 6.8 & 7.4 & $<.001$ \\
\hline Current drinker, $\%$ & 67.3 & 74.5 & 75.8 & 76.9 & 76.4 & $<.001$ \\
\hline Current smoker, \% & 58.1 & 58.1 & 54.8 & 52.7 & 51.2 & $<.001$ \\
\hline High perceived mental stress, $\%$ & 27.9 & 23.7 & 22.9 & 23.2 & 22.8 & $<.001$ \\
\hline Hours of sleep, hour/day & 7.5 & 7.4 & 7.5 & 7.4 & 7.5 & 0.15 \\
\hline Total energy intake, kcal/day & 1,521 & 1,574 & 1,705 & 1,818 & 1,901 & $<.001$ \\
\hline Vegetables intake, g/day & 57.4 & 57.6 & 78.8 & 100.2 & 123.2 & $<.001$ \\
\hline Fruit intake, g/day & 73.0 & 83.3 & 107.9 & 125.6 & 151.2 & $<.001$ \\
\hline Meats intake, g/day & 21.7 & 22.6 & 27.6 & 31.2 & 33.7 & $<.001$ \\
\hline Fish intake, g/day & 37.1 & 36.2 & 44.0 & 51.6 & 58.5 & $<.001$ \\
\hline Total fiber intake, g/day & 9.5 & 9.7 & 11.5 & 13.1 & 14.8 & $<.001$ \\
\hline Sodium intake, mg/day & 1,525 & 1,632 & 1,955 & 2,232 & 2,447 & $<.001$ \\
\hline \multicolumn{7}{|l|}{ Women $(n=55,981)$} \\
\hline Number of subjects & 700 & 3,601 & 14,297 & 17,503 & 19,880 & \\
\hline Age, years & 57.9 & 57.8 & 57.0 & 56.7 & 58.1 & $<.001$ \\
\hline Sport participation $>5$ hour/week, \% & 3.6 & 3.9 & 4.2 & 4.7 & 5.0 & 0.001 \\
\hline Walking time $>1$ hour/day, $\%$ & 44.8 & 48.5 & 51.3 & 50.8 & 53.1 & 0.002 \\
\hline Educated over 18 years old, \% & 6.4 & 6.6 & 6.9 & 6.8 & 9.2 & $<.001$ \\
\hline Total energy intake, kcal/day & 1,233 & 1,259 & 1,357 & 1,426 & 1,525 & $<.001$ \\
\hline Vegetables intake, g/day & 67.9 & 68.7 & 87.2 & 106.2 & 131.0 & $<.001$ \\
\hline Fruit intake, g/day & 98.6 & 109.9 & 128.2 & 145.2 & 171.4 & $<.001$ \\
\hline Meats intake, g/day & 23.3 & 22.4 & 27.3 & 30.5 & 33.6 & $<.001$ \\
\hline Fish intake, g/day & 34.9 & 36.5 & 43.0 & 49.6 & 57.4 & $<.001$ \\
\hline Total fiber intake, g/day & 9.2 & 9.4 & 10.9 & 12.2 & 14.0 & $<.001$ \\
\hline Sodium intake, mg/day & 1,387 & 1,485 & 1,759 & 1,960 & 2,213 & $<.001$ \\
\hline
\end{tabular}

trol SHRSPs a normal diet ${ }^{5)}$.

The underlying mechanisms responsible for the association between seaweed and CVD have still to be clarified. One possible mechanism is an effect of seaweed on the attenuation of blood pressure inverse observed in one animal study ${ }^{4)}$ but not in the other ${ }^{5)}$.
Among the seaweeds, wakame is the most widely consumed in Asian society ${ }^{27}$. Dry wakame (100 g) contains $33 \mathrm{~g}$ of dietary fiber, of which the main constituents are alginates. In vitro studies showed that alginates acted as an ion exchanger in liquids, absorbing sodium ions from and releasing potassium ions into 
Table 2. Multivariable HRs and 95\% CIs of mortality from stroke, stroke types, coronary heart disease and total cardiovascular disease according to the frequency of seaweed intake

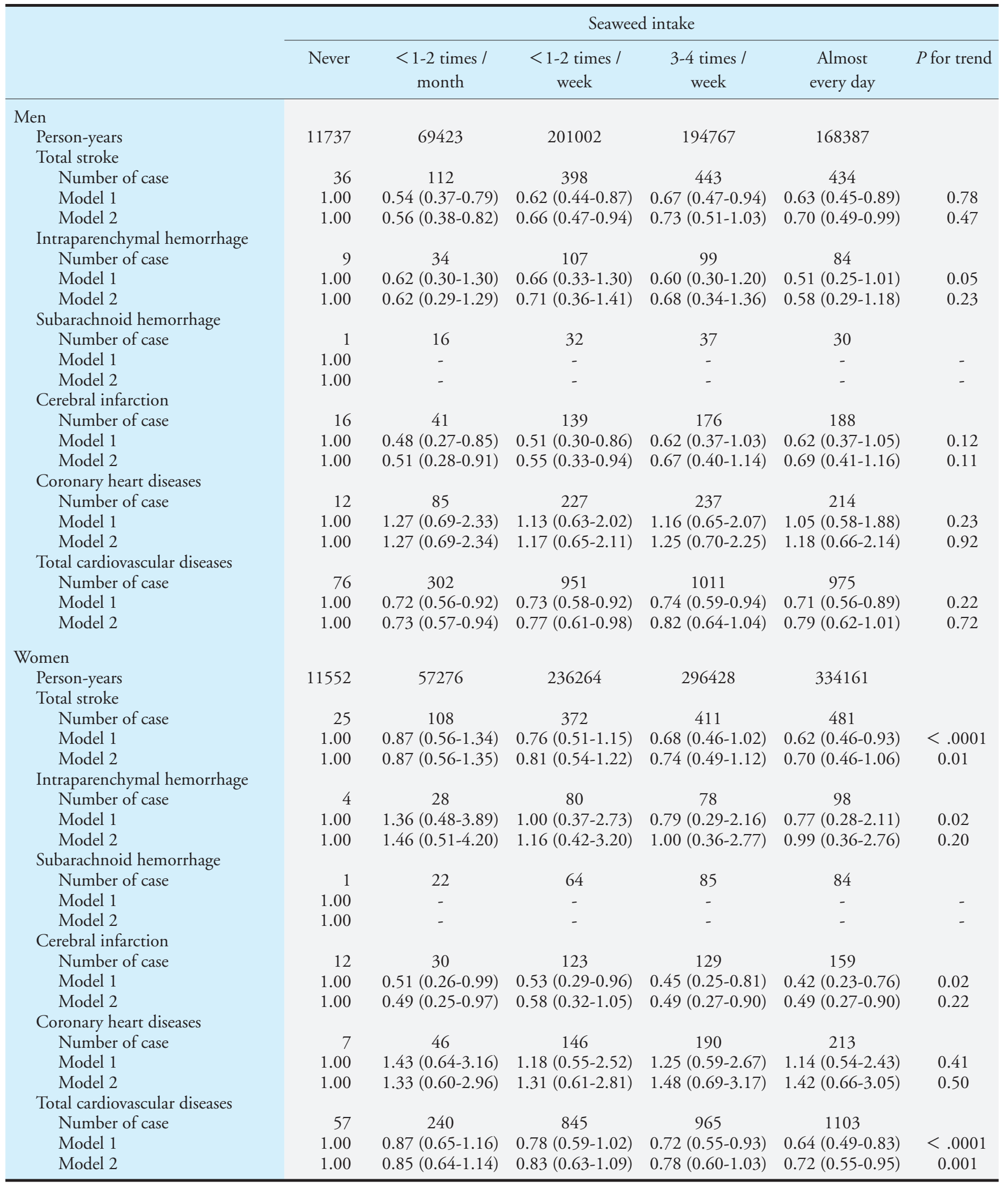

Abbreviations HR, hazard ratio; CI, confidence intervals

Model 1 was stratified jointly by area and adjusted for age.

Model 2 was adjusted further for body mass index, history of hypertension, history of diabetes, alcohol intake, smoking status, perceived mental stress, walking time, sport participation, education levels, total energy, dietary intake of vegetables, fruits, meat, fish, and salt intake. 
liquid media ${ }^{28,29)}$, and an animal study using SHRSPs showed that alginates inhibited intestinal sodium absorption ${ }^{4)}$. Another possible reason for the blood pressure-lowering effect of wakame might be the isolation of peptides from brown seaweed, which had an inhibitory activity for angiotensin 1-converting enzyme, causing an antihypertensive effect in rats ${ }^{6}$. In humans, a randomized double-blind controlled trial demonstrated that among 36 hypertensive Japanese patients (mean age, 71 years), supplementation of $5 \mathrm{~g} /$ day of dried wakame powder significantly lowered the diastolic blood pressure by $9 \mathrm{mmHg}(p<0.01)$ at 4 weeks and by $8 \mathrm{mmHg}(p<0.05)$ at 8 weeks when compared with the no-treatment control group ${ }^{7)}$. Also, another double-blind controlled trial of 62 untreated mild hypertensive patients (mean age, 48 years) demonstrated that the supplementation of seaweed fiber at 4 weeks significantly lowered the mean blood pressure by $10 \mathrm{mmHg}(p<0.01)$ on $12 \mathrm{~g} /$ day and by $11 \mathrm{mmHg}$ on $24 \mathrm{~g} /$ day $(p<0.01)$ but not significantly lowered on $6 \mathrm{~g} /$ day seaweed fiber when compared with placebo treatment ${ }^{29)}$. However, since only 3.5\% fiber intake came from seaweed in general Japanese population ${ }^{15)}$, the inverse association between seaweed intake and risk of CVD mortality was unlikely due to total fiber intake per se.

Other possible mechanisms are the neuroprotective and antioxidant effects of seaweeds. Fucoxanthin, isolated from wakame powder, was dose-dependently attenuated neuronal cell after 4 day injury in the states of hypoxia and reoxygenation under an experimental ischemic model in vitro ${ }^{5)}$. Fucoxanthin also shows stronger antioxidant activity than that of other carotenoids such as $\alpha$-tocopherol ${ }^{30)}$.

Our study has several strengths. First, the JACC study is a large, nationwide, community-based prospective cohort study with almost complete follow-up, which allowed us to examine the associations of seaweed intake with mortality from CVD for the first time. Second, as a confounder, our study adapted to education, one of the key socioeconomic factors. Third, because of the wider distribution of seaweed intake in Japan than in Western countries, we were able to test the potential effect of regular seaweed intake, which has hardly been studied in Western populations.

However, some limitations of the present study warrant discussion. First, seaweed intake may be a reflection of healthy dietary patterns. Previous factor analysis in the JACC study identified seaweed intake consisted of a "vegetable" (healthy) pattern that included fresh fish, vegetables, fungi, potatoes, tofu (soybean curd), and fruits ${ }^{31)}$. Among these foods, fungi, potatoes, and tofu were not adjusted in our analysis, because these intakes were not confounded for the association with mortality from cerebral infarction. Second, the frequency of seaweed intake was evaluated only once, at baseline, although the validity and reproducibility of seaweed intake in this food frequency questionnaire were reasonably good (Spearman correlation coefficients of validity $=0.49$, reproducibility $=0.66)^{22)}$. Thus, we did not consider changes in seaweed intake and cannot elucidate potential misclassification due to lifestyle and dietary change during the follow-up. Third, although the FFQ was moderately and was suitable to assess the categories of food and nutrient intakes but not to assess these amounts ${ }^{22}$. Fourth, we used the mortality data, but not the incidence data as endpoints, which biased toward severe types of CVD and is also liable to misclassification. As for stroke, however, the widespread use of computed tomography scans since the 1980s, even in local hospitals, made the death certificate diagnosis of total stroke and stroke types sufficiently accurate $^{32)}$. As for CHD, approximately one-quarter of deaths from CHD as recorded on death certificates were misdiagnosed ${ }^{25}$, 26) so that the association between seaweed intake and mortality from CHD might be underestimated. The JACC study has shown that the associations dietary intakes of major nutrients and foods with CVD mortality ${ }^{33-35)}$, which were similar to the previous findings from cohort studies with the incidence data ${ }^{36-38)}$.

\section{Conclusion}

The present study revealed that seaweed intake was associated with reduced risk of mortality from total CVD and total stroke, especially cerebral infarction among Japanese men and women.

\section{Acknowledgements}

The authors thank Dr. Kunio Aoki, Professor Emeritus, Nagoya University School of Medicine and the former Chairman of the JACC Study, and Dr. Haruo Sugano, the former Director of the Cancer Institute, Tokyo, who greatly contributed to the initiation of the JACC Study. We also thank Ms. Flaminia Miyamasu, Medical English Communications Center, University of Tsukuba, for editorial assistance. The entire list of JACC Study collaborators was presented previously ${ }^{39)}$.

\section{Notice of Grant Support}

This study has been supported by Grants-in-Aid for Scientific Research from the Ministry of Educa- 
tion, Culture, Sports, Science and Technology of Japan (MEXT) (MonbuKagaku-sho); Grants-in-Aid for Scientific Research on Priority Areas of Cancer; Grants-in-Aid for Scientific Research on Priority Areas of Cancer Epidemiology from MEXT (nos. 61010076, 62010074, 63010074, 1010068, 2151065, 3151064, 4151063, 5151069, 6279102, $11181101,17015022,18014011,20014026$, 20390156, 26293138); and a JSPS KAKENHI (16H06277). This research was also supported by Grants-in-Aid from the Ministry of Health, Labour and Welfare, Health and Labor sciences research grants, Japan (Comprehensive Research on Cardiovascular Disease and Life-Style Related Diseases: H20Junkankitou [Seishuu]-Ippan-013; H23-Junkankitou [Seishuu]-Ippan-005); an Intramural Research Fund (22-4-5) for Cardiovascular Diseases of the National Cerebral and Cardiovascular Center; Comprehensive Research on Cardiovascular Diseases and Life-StyleRelated Diseases (H26-Junkankitou [Seisaku]Ippan-001) and H29-Junkankitou [Seishuu]-Ippan003).

\section{References}

1) Brown ES, Allsopp PJ, Magee PJ, Gill CI, Nitecki S, Strain CR, Mc Sorley EM: Seaweed and human health. Nutr Rev, 2014; 72: 205-216

2) Rajapakse N, Kim SK: Nutritional and digestive health benefits of seaweed. Adv Food Nutr Res, 2011; 64: 17-28

3) Suetsuna K, Maekawa K, Chen JR: Antihypertensive effects of Undaria pinnatifida (wakame) peptide on blood pressure in spontaneously hypertensive rats. J Nutr Biochem, 2004; 15: 267-272

4) Yamori Y, Nara Y, Tsubouchi T, Sogawa Y, Ikeda K, Horie R: Dietary prevention of stroke and its mechanisms in stroke-prone spontaneously hypertensive rats-preventive effect of dietary fibre and palmitoleic acid. J Hypertens Suppl, 1986; 4: 449-452

5) Ikeda K, Kitamura A, Machida H, Watanabe M, Negishi H, Hiraoka J, Nakano T: Effect of Undaria pinnatifida (Wakame) on the development of cerebrovascular diseases in stroke-prone spontaneously hypertensive rats. Clin Exp Pharmacol Physiol, 2003; 30: 44-48

6) Sato M, Hosokawa T, Yamaguchi T, Nakano T, Muramoto K, Kahara T, Funayama K, Kobayashi A, Nakano T: Angiotensin I-converting enzyme inhibitory peptides derived from wakame (Undaria pinnatifida) and their antihypertensive effect in spontaneously hypertensive rats. J Agric Food Chem, 2002; 50: 6245-6252

7) Hata Y, Nakajima K, Uchida J, Hidaka H, Nakano T: Clinical Effects of Brown Seaweed, Undaria pinnatifida (wakame), on Blood Pressure in Hypertensive Subjects. J. Clin. Biochem. Nutr., 2001; 30: 43-53

8) Tsuji K, Oshima S, Matuzaki E, Nakamura A, Innami S, Tezuka T, Suzuki S: Effect of polysacchrides on cholesterol metabolism. Eiyogaku Zasshi, 1968; 26: 113-122
9) Maeda H, Yamamoto R, Hirao K, Tochikubo O: Effects of agar (kanten) diet on obese patients with impaired glucose tolerance and type 2 diabetes. Diabetes Obes Metab, 2005; 7: 40-46

10) Yokota $T$, Nomura $K$, Nagashima $M$, Kamimura N: Fucoidan alleviates high-fat diet-induced dyslipidemia and atherosclerosis in ApoE (shl) mice deficient in apolipoprotein E expression. J Nutr Biochem, 2016; 32: 46-54

11) Shijo Y, Maruyama C, Nakamura E, Nakano R, Shima M, Mae A, Okabe Y, Park S, Kameyama N, Hirai S: Japan Diet Intake Changes Serum Phospholipid Fatty Acid Compositions in Middle-Aged Men: A Pilot Study. J Atheroscler Thromb, 2019; 26: 3-13

12) Maeda H, Hosokawa M, Sashima T, Miyashita K: Dietary combination of fucoxanthin and fish oil attenuates the weight gain of white adipose tissue and decreases blood glucose in obese/diabetic KK-Ay mice. J Agric Food Chem, 2007; 55: 7701-7706

13) Hosokawa M, Miyashita T, Nishikawa S, Emi S, Tsukui T, Beppu F, Okada T, Miyashita K: Fucoxanthin regulates adipocytokine mRNA expression in white adipose tissue of diabetic/obese KK-Ay mice. Arch Biochem Biophys, 2010; 504: 17-25

14) Paxman JR, Richardson JC, Dettmar PW, Corfe BM: Daily ingestion of alginate reduces energy intake in freeliving subjects. Appetite, 2008; 51: 713-719

15) Ministry of Health Labor and Welfare. National Health and Nutrition Survey. 2017; https://www.mhlw.go.jp/ bunya/kenkou/kenkou_eiyou_chousa.htmlAccessed 19/12, 2019

16) Benjamin EJ, Virani SS, Callaway CW, Chamberlain AM, Chang AR, Cheng S, Chiuve SE, Cushman M, Delling FN, Deo R, de Ferranti SD, Ferguson JF, Fornage M, Gillespie C, Isasi CR, Jiménez MC, Jordan LC, Judd SE, Lackland D, Lichtman JH, Lisabeth L, Liu S, Longenecker CT, Lutsey PL, Mackey JS, Matchar DB, Matsushita K, Mussolino ME, Nasir K, O’Flaherty M, Palaniappan LP, Pandey A, Pandey DK, Reeves MJ, Ritchey MD, Rodriguez CJ, Roth GA, Rosamond WD, Sampson UKA, Satou GM, Shah SH, Spartano NL, Tirschwell DL, Tsao CW, Voeks JH, Willey JZ, Wilkins JT, Wu JH, Alger HM, Wong SS, Muntner P; American Heart Association Council on Epidemiology and Prevention Statistics Committee and Stroke Statistics Subcommittee: Heart Disease and Stroke Statistics-2018 Update: A Report From the American Heart Association. Circulation, 2018; 137: e67e492

17) Okada C, Imano $H$, Yamagishi $K$, Cui R, Umesawa $M$, Maruyama K, Muraki I, Hayama-Terada M, Shimizu Y, Sankai T, Okada T, Kiyama M, Kitamura A, Iso H; CIRCS Investigators: Dietary Intake of Energy and Nutrients from Breakfast and Risk of Stroke in The Japanese Population: The Circulatory Risk in Communities Study (CIRCS). J Atheroscler Thromb, 2019; 26: 145-153

18) Shimazu T, Kuriyama S, Hozawa A, Ohmori K, Sato Y, Nakaya N, Nishino Y, Tsubono Y, Tsuji I: Dietary patterns and cardiovascular disease mortality in Japan: a prospective cohort study. Int J Epidemiol, 2007; 36: 600-609

19) Yamori Y, Miura A, Taira K: Implications from and for food cultures for cardiovascular diseases: Japanese food, particularly Okinawan diets. Asia Pac J Clin Nutr, 2001; 
10: $144-145$

20) Murai U, Yamagishi K, Sata M, Kokubo Y, Saito I, Yatsuya $H$, Ishihara J, Inoue M, Sawada N, Iso H, Tsugane S; for the JPHC Study Group: Seaweed intake and risk of coronary heart diseases: the Japan Public Health CenterBased Prospective (JPHC) Study. Am J Clin Nutr, 2019; 110: 1449-1455

21) Tamakoshi A, Ozasa K, Fujino Y, Suzuki K, Sakata K, Mori M, Kikuchi S, Iso H, for the JACC Study Group Cohort: Profile of the Japan Collaborative Cohort Study at Final Follow-up. J Epidemiol, 2013; 23: 227-232

22) Date C, Fukui M, Yamamoto A, Wakai K, Ozeki A, Motohashi Y, Adachi C, Okamoto N, Kurosawa M, Tokudome Y: Reproducibility and validity of a selfadministered food frequency questionnaire used in the JACC study. J Epidemiol, 2005; 15: S9-23

23) Walter W: Nutritional epidemiology. Oxford Oxford University Press, New York, USA, 2013; 96-141

24) Iso H, Kubota Y: Nutrition and disease in the Japan Collaborative Cohort Study for Evaluation of Cancer (JACC). Asian Pac J Cancer Prev, 2007; 8: s35-80

25) Baba S, Ozawa H, Sakai Y, Terao A, Konishi M, Tatara K: Heart disease deaths in a Japanese urban area evaluated by clinical and police records. Circulation, 1994; 89: 109115

26) Saito I: Review of death certificate diagnosis of coronary heart disease and heart failure in Japan. Japanese Journal of Public Health, 2004; 51: 909-916

27) A guide to the seaweed; industry. 441: http://www.fao. org/docrep/006/y4765e/y4765e0b.htm. (accessed on 10 feb 2019)

28) Kloareg B, Demarty M, Mabeau, S: Ion-exchange properties of isolated cell walls of brown algae. Journal of Experimental Botany, 1987; 38: 1652-1662

29) Krotkiewski M, Aurell M, Holm G, Grimby G, Szczepanik J: Effects of a sodium-potassium ion-exchanging seaweed preparation in mild hypertension. Am J Hypertens, 1991; 4: 483-488

30) Sachindra NM, Sato E, Maeda H, Hosokawa M, Niwano Y, Kohno M, Miyashita K: Radical scavenging and singlet oxygen quenching activity of marine carotenoid fucoxanthin and its metabolites. J Agric Food Chem, 2007; 55: 8516-8522
31) Maruyama K, Iso H, Date C, Kikuchi S, Watanabe $Y$, Wada Y, Inaba Y, Tamakoshi A; JACC Study Group: Dietary patterns and risk of cardiovascular deaths among middle-aged Japanese: JACC Study. Nutr Metab Cardiovasc Dis, 2013; 23: 519-527

32) Sankai T, Miyagaki T, Iso H, Shimamoto T, Iida M, Tanigaki M, Naito Y, Sato S, Kiyama M, Kitamura A: A population-based study of the proportion by type of stroke determined by computed tomography scan. Nippon Koushu eisei Zasshi, 1991; 38: 901-909

33) Nagura J, Iso H, Watanabe $Y$, Maruyama K, Date C, Toyoshima H, Yamamoto A, Kikuchi S, Koizumi A, Kondo T, Wada Y, Inaba Y, Tamakoshi A: Fruit, vegetable and bean intake and mortality from cardiovascular disease among Japanese men and women: the JACC Study. Br J Nutr, 2009; 102: 285-292

34) Yamagishi K, Iso H, Yatsuya H, Tanabe N, Date C, Kikuchi S, Yamamoto A, Inaba Y, Tamakoshi A: Dietary intake of saturated fatty acids and mortality from cardiovascular disease in Japanese: the Japan Collaborative Cohort Study for Evaluation of Cancer Risk (JACC) Study. Am J Clin Nutr, 2010; 92: 759-765

35) Umesawa M, Iso $H$, Date C, Yamamoto A, Toyoshima $H$, Watanabe Y, Kikuchi S, Koizumi A, Kondo T, Inaba Y, Tanabe N, Tamakoshi A: Dietary intake of calcium in relation to mortality from cardiovascular disease: the JACC Study. Stroke, 2006; 37: 20-26

36) Takachi R, Inoue M, Ishihara J, Kurahashi N, Iwasaki M, Sasazuki S, Iso H, Tsubono Y, Tsugane S: Fruit and vegetable intake and risk of total cancer and cardiovascular disease: Japan Public Health Center-Based Prospective Study. Am J Epidemiol, 2008; 167: 59-70

37) Yamagishi K, Iso H, Kokubo Y, Saito I, Yatsuya H, Ishihara J, Inoue M, Tsugane S: Dietary intake of saturated fatty acids and incident stroke and coronary heart disease in Japanese communities: the JPHC Study. Eur Heart J, 2013; 34: 1225-1232

38) Umesawa M, Iso H, Ishihara J, Saito I, Kokubo Y, Inoue M, Tsugane S: Dietary calcium intake and risks of stroke, its subtypes, and coronary heart disease in Japanese: the JPHC Study Cohort I. Stroke, 2008; 39: 2449-2456

39) The JACC Study Group. JACC study: http://publichealth.med.hokudai.ac.jp/jacc/ Accessed 18/2, 2020 